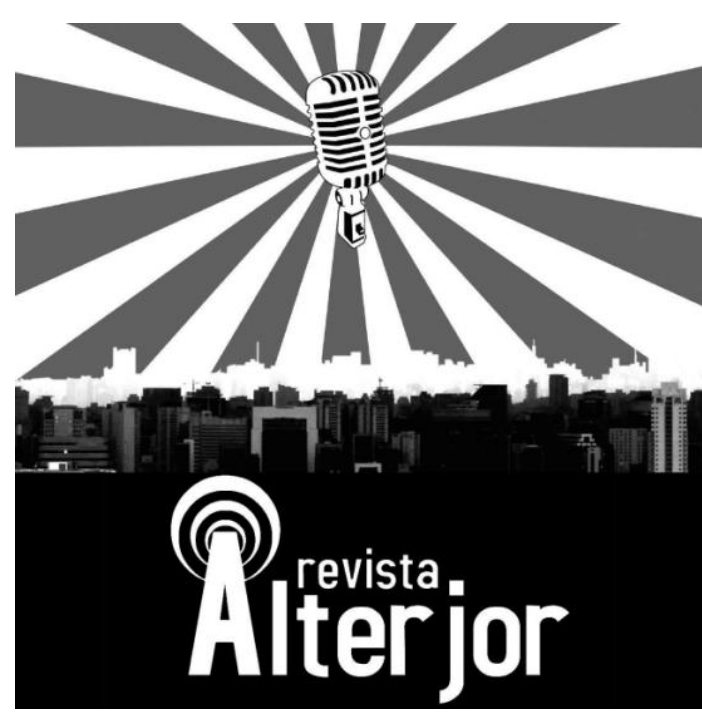

$\underline{\text { RESENHA }}$

\title{
SACODE BRASIL!!! ASSIM COMEÇOU A LAVA JATO
}

\author{
Paulo Celso da Silva ${ }^{1}$
}

\begin{abstract}
RESUMO: O ano de 2019 ficou marcado pelo turbilhão que abalou as certezas de que a corrupção seria punida. O jornal online The Intercept Brasil publica no meio do ano, a primeira matéria na qual indica que a imparcialidade e a honestidade das investigações da Operação Lava Jato estavam comprometidas pela série de atitudes, mandos e desmandos de seu comando, o ex-juiz e ex-ministro Sergio Moro e do exprocurador e ex-coordenador da Operação, Deltan Dallagnol. O livro dividido em dois momentos o primeiro narrado pela jornalista Letícia Duarte e o segundo com matérias veiculadas, inclusive duas inéditas, apresenta parte do cotidiano dos jornalistas que protagonizaram os acontecimentos que sacudiram o meio jornalístico e político internacional.
\end{abstract}

PALAVRAS-CHAVE: Operação Lava Jato. The Intercept Brasil. Vaza Jato. Corrupção. Política internacional.

ABSTRACT: The year of 2019 was marked by the turmoil that put in check the certainties that corruption would be punished. The online newspaper The Intercept Brasil published in the middle of the year the first article in which indicates that the impartiality and honesty of the investigations of Lava Jato Operation were compromised by a series of attitudes, mandates and dismissals of its command, the former judge and ex - Minister Sergio Moro and the former prosecutor and former Operation coordinator, Deltan Dallagnol. The book is divided into two moments: the first narrated by journalist Letícia Duarte and the second with published material, including two unpublished ones, the book presents part of the daily lives of journalists who starred in the events that shook the international journalistic and political environment

KEYWORDS: Car Wash Operation. The Intercept Brasil. Vaza Jato. Corruption. International politics.

\footnotetext{
${ }^{1}$ Professor do PPG Comunicação e Cultura da Universidade de Sorocaba. Membro da RED ALEC - Red Internacional América Latina, África, Europa, El Caribe - "Territorio(s), Poblaciones Vulnerables y Políticas Públicas”. E-mail: paulo.silva@ prof.uniso.br
}

Revista ALTERJOR

Grupo de Estudos Alterjor:Jornalismo Popular e Alternativo (ECA-USP)

Ano Io Volume ol Edição 23 Janeiro-Juho de 2021

Avenida Professor Lúcio Martins Rodriģues, 443, Cidade Universitária, São Paulo, CEP: 05508-020 

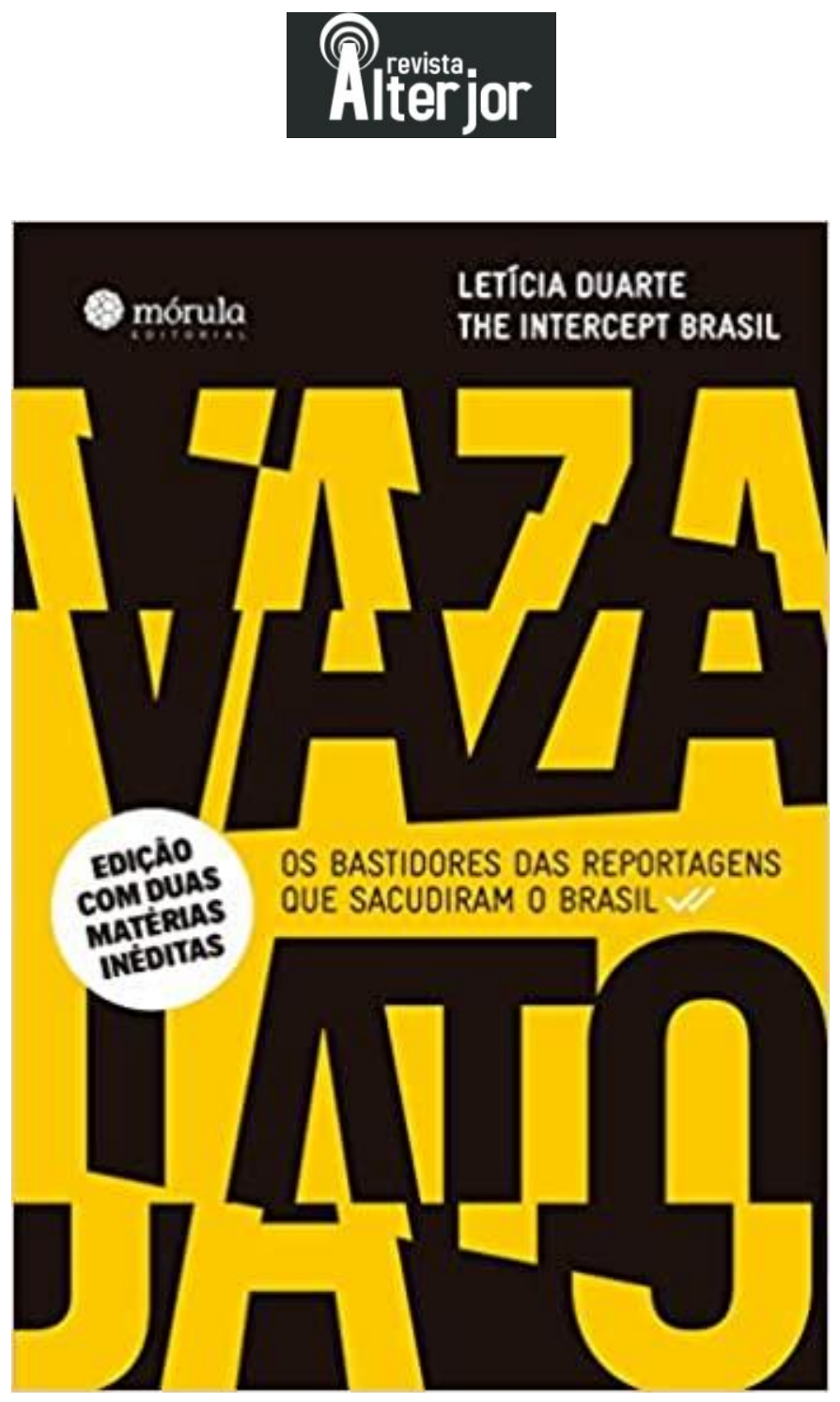

"It was militancy, not investigation or journalism."

Deltan Dallagnol para Darren Loucaides da Wired em 13.11.2020 06:00 AM

Domingo, 9 de julho de 2019, perto das 17 horas, o jornal online The Intercept Brasil inicia a sua série de reportagens revelando facetas da Operação Lava Jato que então, eram de desconhecimento do público (inter)nacional. Leitores e Mídias em geral, de esquerda ou direito, receberam incrédulos fatos, áudio, conversas em que a tão falada e aceita aura de imparcialidade dos componentes da operação anticorrupção, faziam transpassar em suas ações sempre acompanhadas e registradas pelos meios de comunicação. Assim foi durante cinco anos.

Revista AL TERJOR

Grupo de Estudos Alterjor: Jornalismo Popular e Alternativo (ECA-USP)

Ano 10 Volume Ol Edição 23 Janeiro-Junho de 202l

Avenida Professor Lúcio Martins Rodrig̉ues, 443, Cidade Universitária, São Paulo, CEP: 05508-020 


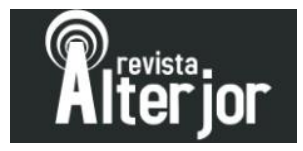

Foram mais 100 matérias publicadas desde o recebimento dos arquivos por um hacker que se identificava como @BrazilBaronil. E tudo começou no dia 12 de maio de 2019 quando Manuela D’Ávila recebeu a indicação de mensagem no App Telegram em seu celular, era Cid Gomes que precisava conversar urgente.

Ela ligou. Ocupado. Ele manda outra mensagem: Consegue confiar em mim? Sim, 100\%. E Cid continua: "olha, eu não sou o Cid. Eu entrei no Telegram dele e no seu. Mas eu tenho uma coisa que muda o Brasil hoje” (pág. 11)

Com essa primeira conversa de @BrazilBaronil e Manuela D’Ávila, começa o livro escrito durante a pandemia do Covid-19, como a própria autora, Letícia Duarte, informou em uma live no mês de novembro em companhia de Leandro Demori, jornalista e editor executivo do Intercept Brasil.

O livro está estruturado em duas partes: a primeira com a história narrada pela jornalista Letícia Duarte (até a pág. 118) e a segunda com dez matérias já publicadas no site do Intercept e duas ainda inéditas, sendo: 'PQP. MATÉRIAS FURADAS NA INTERNET'. Como a lava jato caiu na mentira de internet e esperava prender em flagrante o ex-presidente Lula por roubar um objeto que era dele mesmo' (páginas 242 a 263), e 'UM TRANSATLÂNTICO'. O namoro entre a Lava Jato e a Rede Globo' (páginas 264 a 300). Completam a obra os agradecimentos às redações da Agência Pública, BuzzFeed News Brasil, El País, Folha de S. Paulo, UOL, Veja e ao jornalista Reinaldo Azevedo. Além das instituições: Associação Brasileira de Imprensa, Federação Nacional dos jornalistas, Instituto Vladimir Herzog, OAB, Sindicato dos jornalistas de São Paulo, Centros Acadêmicos XI de Agosto (Direito-USP) Wladimir Herzog (Casper Líbero) e Lupe Cotrim (ECA-USP). A edição encerra com imagens da equipe Intercept, feitas pelo fotografo Cristian Braga, no dia 09 de junho de 2019.

Para escrever a primeira parte do livro, a equipe do Intercept escolheu a jornalista Letícia Duarte porque ela não participa do time editorial e ela pode entrevistar os componentes do Intercept, assim como outras pessoas que poderiam contribuir para reconstruir a narrativa do período. Nas palavras da jornalista: "reconstruir as cenas, é importante pensar nessa construção jornalística... levar o leitor para o centro dos 


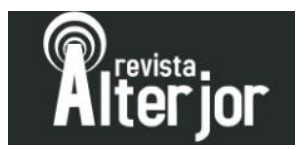

acontecimentos, como se estivesse fazendo parte da própria história". (LIVE \#VAZAJATO ).

As conversas apresentadas no livro e a narrativa construída contribuem para o leitor ter ideia de como uma investigação jornalística é feita no cotidiano da redação e da vida pessoal dos jornalistas. Uma vez que é muito comum as pessoas terem ideia de que é um trabalho cheio de glamour e prêmios constantes.

Ao contrário, as narrativas mostram acertos e erros humanos e fica mais fácil compreender porque no $42^{\circ}$ Prêmio Vladimir Herzog, a equipe envolvida nas matérias ganhou na categoria 'PRODUÇÃO JORNALÍSTICA EM TEXTO' - FBI e a LavaJato (série Vaza Jato) | Natalia Viana, Mariam Saleh, Andrew Fishman, Alice Maciel, Rafael Neves, Marina Amaral, Bruno Fonseca e Larissa Fernandes (Agência Pública, em parceria com The Intercept Brasil).

Para que o leitor tenha ideia de que nem tudo é planejado ou está sob controle o tempo todo, desde que Glenn Greenwald recebeu os de @BrazilBaronil em seu aplicativo em maio, começou uma verdadeiro epopeia para saber do que se tratava, exatamente, qual a ordem das mensagens e como elas se ligavam aos áudios. A equipe tinha a intenção de publicar a primeira em 11 de junho, entretanto, uma mensagem de @BrazilBaronil “cobrando a publicação por ter interesse em investimentos na Bolsa de Valores" colocou todo mundo em alerta. Greenwald não falou quando publicaria, mas em reunião com os jornalistas, acertaram que o domingo a noite seria o ideal, uma vez que impossibilitaria aplicações e quando as bolsas abrissem todos já teriam as notícias.

Após a publicação e a repercussão que ela trouxe, inclusive entre demais meios de comunicação, a equipe do Intercept propõe a alguns deles algo diferente: que fossem parceiros na garimpagem do extenso material que ainda restava verificar. A parceria menos provável entre eles e a Revista Veja, aconteceu. Entretanto, as parcerias não eram isentas de conflitos.

No estranho momento que todos nós vivemos, desde as primeiras medidas do presidente eleito em 2018, no qual as instituições públicas foram questionadas por ele e seus fanáticos seguidores/apoiadores - Câmaras dos Deputados, Senado, Supremo 


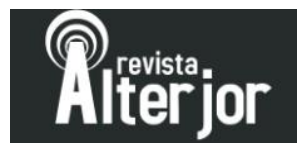

tribunal Federal, por exemplo - denunciar o trunfo da direita brasileira não ficaria sem represálias. As equipes de trabalho, alocadas na sede do Intercept Brasil, desconfiavam e temiam todas as possibilidades e por isso foi criada a Editoria da Paranoia, para indicar as normas de segurança da redação, como por exemplo não usar a internet no mesmo computador em que está fazendo o levantamento das mensagens, guardar os celulares em outros cômodos para evitar, possíveis, escutas da ABIN (Agência Brasileira de Inteligência).

Os órgãos ligados à Justiça e ao governo brasileiro tentaram a intimidação, com o MPF (Ministério Público Federal) denunciando o jornalista Glenn Greenwald e mais seis pessoas acusados de invadir celulares do ex-juiz e ex-ministro Sergio Moro e do exprocurador e ex-coordenador da Operação Lava Jato, Deltan Dallagnol.

O livro é uma espécie de retrato dos momentos iniciais da Vaza Jato, em nenhum momento encerra ou quer encerrar os acontecimentos, mesmo porque nem mesmo o futuro da Operação Lava Jato está garantido, pois seus principais atores, Moro e Dallagnol, já fazem parte do passado da Operação. O ex-juiz e ex-ministro ainda deverá voltar aos tribunais para retornar o julgamento de suspeição, talvez fevereiro de 2021, como veicularam alguns meios de comunicação. De todas as formas, as mensagens e gravações do aplicativo Telegran, publicadas das investigações do Intercept Brasil, serão peças importantes do processo que decidirá se houve ou não parcialidade do ex-juiz no caso de Lula da Silva.

... Quarta - feira, 07 de outubro de 2020, o presidente do Brasil declara: "Eu acabei com a Lava Jato, porque não tem mais corrupção no governo. Eu sei que isso não é virtude, é obrigação"....

Um livro importante, se pensarmos didaticamente nos cursos de jornalismo que podem se aproveitar para discutir e refletir temas como ética profissional, metodologias de trabalho, técnicas de narração, meios de comunicação na história recente brasileira, entre tantas possibilidades abertas.

Contudo, um livro, um documentário são representações do vivido, registros nos quais uma visão dos fatos e do mundo são oferecidos para REFLEXÃO. Como ouvimos de 


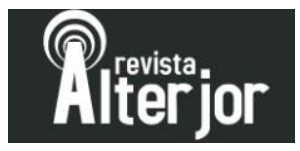

nossos pais e avós, quando algo não estava do agrado deles e éramos chamados para explicar o acontecido, a história tem três versões: a minha, a sua e a certa. Portanto, leitores, jornalistas, alunos cabe a cada um o trabalho de encontrar a versão que mais se aproxima do acontecido.

O livro indica ainda que os diretos autorais da Vaza Jato foram vendidos para virar um filme dirigido por José Padilha. Vamos esperar.

\section{Referências}

DUARTE, Letícia. The Intercept Brasil. Vaza Jato: Os bastidores das reportagens que sacudiram o Brasil. Rio de Janeiro: Mórula Editorial, 2020.

G1 - Globo. Bolsonaro diz que 'acabou' com operação Lava Jato porque governo 'não tem mais corrupção'. Disponível em:

https://g1.globo.com/politica/noticia/2020/10/07/bolsonaro-diz-que-acabou-com-a-operacaolava-jato-porque-governo-nao-tem-mais-corrupcao.ghtml . Acesso em $31 \mathrm{dez} .2020$.

LIVE \#VAZAJATO: os bastidores das reportagens que sacudiram o Brasil. Disponível em: https://www.youtube.com/watch?v=KUc_KOxW3mY . Acesso em 31 dez. 2020.

LOUCAIDES, Darren. The Scammer Who Wanted to Save His Country. Disponível em: https://www.wired.com/story/brazil-hacker-bolsonaro-car-wash-leaks/ . Acesso em $31 \mathrm{dez}$. 2020.

PREMIADOS - $42^{\circ}$ PRÊMIO VLADIMIR HERZOG. Disponível em http://premiovladimirherzog.org/vencedores-42-premio-vladimir-herzog/ Acesso em $31 \mathrm{dez}$. 2020. 